\section{International Scientific Journal Theoretical \& Applied Science}

p-ISSN: 2308-4944 (print) e-ISSN: 2409-0085 (online)

Year: $2018 \quad$ Issue: 02 Volume: 58

Published: $28.02 .2018 \quad$ http://T-Science.org

SECTION 32. Jurisprudence.
Elena Toktonalievna Atamkulova, candidate of juridical science assistant professor of department of theory of law and government of Osh state university of Kyrgyz Republic

Mederbek Payisbekovich Orolbaev, Head of department of criminal procedure of Academy of Ministry of Interrior Affairs of Kyrgyz Republic

Ulanbek Askaralievich Esenov, Head of Researching department of Academy of Ministry of Interrior Affairs of Kyrgyz Republic

Shumkar Alimjanovich Esenkulov, Senior inspector editor of Researching department of Academy of Ministry of Interrior Affairs of Kyrgyz Republic

\title{
DEPOSITING EVIDENCE AS ONE OF THE NOVELS OF THE CRIMINAL PROCEDURE LEGISLATION OF THE KYRGYZ REPUBLIC
}

Abstract: In the article the new institute "deposition of testimony" in the Criminal Procedure Code of the Kyrgyz Republic was considered, which will come into force on January 1, 2019. In the work, the author tried to disclose the features of depositing the testimony, to reveal the distinctive features from the usual interrogation, and also the ways of solving the problem were suggested in the case of the absence of the witness on call.

Key words: criminal procedure code, deposition of testimony, interrogation, suspect, protocol of the court session.

Language: Russian

Citation: Atamkulova ET, Orolbaev MP, Esenov UA, Esenkulov SA (2018) DEPOSITING EVIDENCE AS ONE OF THE NOVELS OF THE CRIMINAL PROCEDURE LEGISLATION OF THE KYRGYZ REPUBLIC. ISJ Theoretical \& Applied Science, 02 (58): 114-117.

Soi: http://s-o-i.org/1.1/TAS-02-58-24 Doi: crossef https://dx.doi.org/10.15863/TAS.2018.02.58.24

\section{ДЕПОНИРОВАНИЕ ПОКАЗАНИЙ КАК ОДНА ИЗ НОВЕЛЛ УГОЛОВНО-ПРОЦЕССУАЛЬНОГО ЗАКОНОДАТЕЛЬСТВА КЫРГЫЗСКОЙ РЕСПУБЛИКИ}

Аннотация: В статье рассмотрен нововведённый институт «депонирование показаний» в УПК КР, который вступит в силу с первого января 2019 года. В работе, автор попытался раскрыть особенности депонирования показания, выявить отличительные признаки от обычного допроса, а также был предложены пути решения проблемы в случае неявки свидетеля по вызову.

Ключевые слова: уголовно-прочессуальный кодекс, депонирование показаний, допрос, подозреваемый, протокол судебного заседания.

\section{Introduction}

Новый Уголовно-процессуальный кодекс [1], который будет введен в действие с 1 января 2019 года, содержит достаточное количество новых институтов, норм и положений. Но наряду с этим, разработчики данного закона не ограничились лишь дополнением, о чем свидетельствует упразднение одного из стадий уголовного процесса - возбуждения уголовного дела.

\section{Materials and Methods}

Следует отметить, что существенным изменениям подвергся институт следственных действий, который был разделен на две части : следственные действия и специальные следственные действия.

Специальные следственные действия в основном состоят из оперативно-розыскных мероприятий, которые были «процессуализированы» и переведены в плоскость следственных действий. 
Кроме этого, особого внимания заслуживает нововведённый институт «депонирования показаний» [2].

Согласно ст. 5 УПК КР, депонирование показаний свидетеля и потерпевшего проведение в ходе досудебного производства следственным судьей допроса свидетеля или потерпевшего по ходатайству одной из сторон с целью заблаговременного обеспечения (сохранения) судебных доказательств при наличии оснований, что в силу объективных причин впоследствии допросить их в ходе судебного разбирательства станет невозможным, либо необходимости обеспечения безопасности свидетеля или потерпевшего [8, с. 32].

Депонирование показаний, по сути, представляет собой разновидность допроса, однако, следует отметить, что имеются существенные отличия от обычного допроса по своим основаниям; по кругу инициаторов данного процессуального действия, а также по субъекту, правомочному осуществлять депонирование показаний.

У многих, наверняка возникает вопрос: «зачем надо было вводить данный институт? Был допрос и весьма успешно обходились без депонирования».

Но ответ на данный вопрос вызывает необходимость в обсуждении множества проблем, с которыми сталкиваются должностные лица, осуществляющие досудебное производство.

Самой распространенной проблемой в уголовном судопроизводстве выступает обеспечение явки лиц к следователю, суду для дачи показаний [3, с. 28]. Прежде всего, это касается свидетелей и потерпевших. Однако, при этом необходимо отметить, что основания вовлечения данных лиц в уголовное судопроизводство различны: если свидетель незаинтересованное в исходе дела лицо, обязанное давать правдивые показания, то потерпевший является самым заинтересованным лицом в исходе дела, зачастую именно он сам и выступает инициатором начала досудебного производства.

Как показывает многолетняя практика, существует ряд обстоятельств, которые препятствуют явке потерпевшего и свидетеля в суд:

- отсутствие постоянного место жительства в Кыргызской Республике и возможности каждый раз являться по вызову;

- частые заграничные командировки, связанные с профессиональной деятельностью лица;

- состояние здоровья лица, препятствующее своевременной явке (в таких случаях допрос проводится по месту нахождения лица);
- в целях обеспечения безопасности (если есть основания полагать, что жизнь и здоровье лица может быть подвергнуто опасности, то адвокат обязан официально обратиться к судье о принятии мер по обеспечению их безопасной явки);

- морально-психологических соображений (неоднократный допрос несовершеннолетнего потерпевшего, заставляющего его снова и снова вспоминать детали совершенного деяния могут оказать негативное воздействие на психику несовершеннолетнего и т.д.).

И нельзя не озвучить и это обстоятельство, так как оно также имеет место быть и довольно часто: лица, вовлеченные в досудебное производство в качестве свидетеля, имеющие постоянную работу не могут в любое время по вызову следователя, суда явиться к ним. Для этого ему необходимо получить разрешение начальства, а общеизвестно, что руководители бывают разными: кто-то с пониманием отнесется, а кому-то это будет «пустой тратой времени» и не дать разрешения. При этом вполне возможно, что данное лицо является одним из ключевых свидетелей по делу. Но здесь, мы бы хотели акцентировать на организацию своего времени следователем, уполномоченным должностным лицом органа дознания, то есть должно быть четкое, детальное планирование всех предстоящих дел во избежание пустой траты времени как своего, так и свидетеля. Такое отношение следователя зачастую и порождает у граждан недоверие и нежелание оказывать содействие, сотрудничать.

Глава 26 Уголовно-процессуального кодекса посвящена «Депонированию показаний» и согласно ст. 198 УПК КР, по ходатайству защитника и участников процесса со стороны защиты следственный судья [4] в ходе досудебного производства допрашивает потерпевшего, свидетеля об известных им обстоятельствах по уголовному делу и (или) делу о проступке. Защитник и участники процесса со стороны защиты обращаются с ходатайством о депонировании непосредственно в суд.

В исключительных случаях, если имеются основания полагать, что:

- более поздний допрос потерпевшего, свидетеля в досудебном производстве либо в судебном заседании при рассмотрении дела по существу может стать невозможным в силу объективных причин, связанных с опасностью для жизни и здоровья;

- тяжелой болезнью потерпевшего, свидетеля;

- предстоящим их выездом за пределы или постоянным проживанием за пределами Кыргызской Республики, такой потерпевший, свидетель может быть допрошен следственным 
судьей по ходатайству следователя, уполномоченного должностного лица органа дознания.

При необходимости депонирования показаний, следователь, должностное лицо органа дознания, участники процесса со стороны защиты заявляют ходатайства перед следственным судьей о производстве депонирования показаний [7, с. 57].

Следователь, должностное лицо органа дознания обязаны представить следственному судье материалы, подтверждающие необходимость в депонировании показаний.

Данное ходатайство изучается следственным судьей в течение трех суток и по результатам изучения выносит постановление об удовлетворении ходатайства либо отказе в таковом. Во втором случае, участники имеют право обжаловать указанное решение в апелляционном порядке.

В случае удовлетворения ходатайства, не позднее трех суток, следственный судья допрашивает потерпевшего и свидетеля по общим правилам допроса в ходе судебного разбирательства [9].

Повторный допрос указанных лиц не допускается, он возможен только если необходимы уточнения.

Из вышеуказанного, мы приходим к выводу, что депонирование показаний имеет некоторые отличия от обычного простого допроса. Так:

1. депонирование показание осуществляется исключительно следственным судьей;

2. депонированные показания следственным судьей исследуются в ходе судебного разбирательства и могут быть положены в основу принятого решения;

3. депонирование показание проводится в судебном заседании с составлением соответствующего протокола;

4. после окончания допроса следственный судья направляет протокол судебного заседания о депонировании показаний потерпевшего, свидетеля следователю, уполномоченному должностному лицу органа дознания для приобщения к материалам уголовного дела $[5$, с. $4]$.

\section{Conclusion}

Подводя итог изложенному, следует отметить, что институт депонирования показаний является одним из необходимых, нужных и своевременно введенных институтов, с учетом криминогенной ситуации, отношения людей к выполнению своего гражданского долга, а также эффективно построенной системы противодействия расследованию и раскрытию уголовных дел и проступков. В связи с чем, считаем, что данный институт является не только необходимым, но и обязательным, что способствует полному, всестороннему и объективному исследованию обстоятельств дела, защите прав пострадавших от совершенного преступления (проступка), а также принятию действенных мер для возмещения ущерба, причиненного преступлением, а самое главное соответствие внутреннего законодательства международным стандартам справедливого правосудия [6, с. 409].

Продолжая тему допроса, хотелось бы остановиться на том, что законодатель предусмотрел еще один вид допроса -допрос с использованием технических средств в режиме видеосвязи (дистанционный допрос).

В соответствии со ст. 194 УПК КР, допрос потерпевшего, свидетеля может быть произведен с использованием технических средств в режиме видеосвязи (дистанционный допрос) с вызовом его в орган досудебного производства того района, на территории которого он находится либо проживает. В ходе дистанционного допроса участники процессуального действия в прямой трансляции непосредственно воспринимают показания допрашиваемого лица.

Дистанционный допрос производится в случаях:

1) невозможности непосредственного прибытия лица в орган досудебного производства по месту расследования уголовного дела и (или) дела о проступке по состоянию здоровья или по другим уважительным причинам;

2) необходимости обеспечения безопасности лица при судебном рассмотрении дела.

Решение о производстве дистанционного допроса принимается следователем, уполномоченным должностным лицом органа дознания, в производстве которых находится дело, по собственной инициативе или по ходатайству участников процесса.

Решение о производстве дистанционного допроса в ходе судебного разбирательства принимается судом по ходатайству сторон, о чем выносится мотивированное постановление (определение).

Использование при дистанционном допросе технических средств и технологий должно обеспечивать надлежащее качество изображения и звука, а также информационную безопасность. Участникам допроса должна быть обеспечена возможность задавать вопросы и получать ответы от лиц, участвующих в дистанционном допросе [10, с. 39].

Ход и результаты допроса, проведенного в режиме видеосвязи, отражаются в протоколе, составляемом следователем, уполномоченным должностным лицом органа дознания того района, на территории которого находится 


\begin{tabular}{l|lr|ll|ll} 
& ISRA (India) & $=\mathbf{1 . 3 4 4}$ & SIS (USA) & $=\mathbf{0 . 9 1 2}$ & ICV (Poland) & $=\mathbf{6 . 6 3 0}$ \\
Impact Factor: & ISI (Dubai, UAE) $=\mathbf{0 . 8 2 9}$ & PUHL (Russia) $=\mathbf{0 . 2 0 7}$ & PIF (India) & $=\mathbf{1 . 9 4 0}$ \\
& GIF (Australia) & $=\mathbf{0 . 5 6 4}$ & ESJI (KZ) & $=4.102$ & IIBI (India) & $=\mathbf{4 . 2 6 0}$ \\
& JIF & $=\mathbf{1 . 5 0 0}$ & SJIF (Morocco) & $=\mathbf{2 . 0 3 1}$ & & \\
\hline
\end{tabular}

допрашиваемый.

В протоколе дистанционного допроса делается отметка о технических средствах видеозаписи, с помощью которых производится дистанционный допрос.
В целях обеспечения безопасности лицо по его ходатайству может быть допрошено в режиме видеосвязи с изменением внешности и голоса, исключающим его узнавание.

\section{References:}

1. (2018) Ugolovno-protsessualnyiy kodeks Kyirgyizskoy Respubliki ot 30 iyunya 1999 goda \#62, v sootvetstvii s Zakonom KR ot 24 yanvarya 2017 goda \#10, s 1 yanvarya 2019 goda utrachivaet silu ( po sostoyaniyu na 1 yanvarya 2018 goda).

2. (2018) Deponirovanie v perevode s latinskogo oznachaet «kladu, ostavlyayu» - protsess organizovannogo hraneniya chego -libo. Available: https:\|ru.v.wikipedia.org >wiki>. (Accessed: 10.02.2018).

3. Omirtayulyi N. (2017) Deponirovanie v hode dosudebnogo proizvodstva pokazaniy poterpevshego i svidetelya. - Almatyi, 2017. p. 28.

4. (2018) Sledstvennyiy sudya - sudya, primenyayuschiy meryi, ogranichivayuschie prava i svobodyi podozrevaemogo, obvinyaemogo, osuschestvlyayuschiy sudebnyiy kontrol za zakonnostyu protsessualnyih deystviy i resheniy upolnomochennogo dolzhnostnogo litsa organa doznaniya, sledovatelya, rukovoditelya sledstvennogo podrazdeleniya, prokurora (st. 5 UPK KR).

5. Kalnitskiy V.V. (2003) Sledstvennyie deystviya. - Omsk, 2003. - p. 4.

6. (2012) Standartyi spravedlivogo pravosudiya (mezhdunarodnyie i natsionalnyie praktiki) / koll. avtorov pod red. d.yu.n. T.G. Morschakovoy. - M., 2012. - p. 407-409.

7. Saveleva M.V. (2012) Sledstvennyie deystviya. Uchebnik dlya magistrov. - Moscow. - p. 57.

8. Sheyfer S.A. (2001) Sledstvennyie deystviya. Sistema i protsessualnaya forma. - M., 2001. p. 32.

9. Zazhitskiy V. (1985) Predmet issledovaniya v ugolovnom sudoproizvodstve // Sov. yustitsiya. 1985. -p. 24.

10. Marfitsin P.G., Bezrukov S.S. (2001) Otnositelnaya opredelennost $\mathrm{v}$ ugolovnoprotsessualnom prave i predelyi usmotreniya sledovatelya: Uchebnoe posobie. Omsk: Omskaya akademiya MVD Rossii, 2001. - p. 39. 